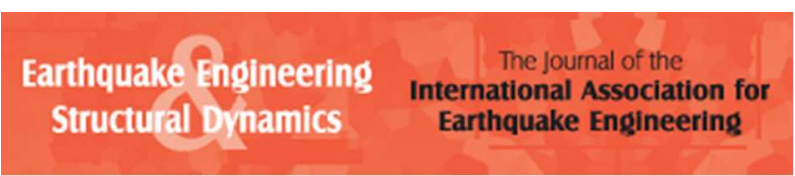

\title{
Extending the application of integral frame abutment bridges in earthquake prone areas by using novel isolators of recycled materials
}

\begin{tabular}{|r|l|}
\hline Journal: & Earthquake Engineering and Structural Dynamics \\
\hline Manuscript ID & EQE-15-0255.R1 \\
\hline Wiley - Manuscript type: & Research Article \\
\hline Date Submitted by the Author: & n/a \\
\hline Complete List of Authors: & $\begin{array}{l}\text { Mitoulis, Stergios; University of Surrey, Civil and Environmental } \\
\text { Engineering } \\
\text { Palaiochorinou, Anastasia; Aristotle University of Thessaloniki, Civil } \\
\text { Engineering } \\
\text { Georgiadis, Ilias; Projects Link Contracting Co L.L.C., Construction } \\
\text { Argyroudis, Sotiris; Aristotle University of Thessaloniki, Civil Engineering }\end{array}$ \\
\hline Keywords: & $\begin{array}{l}\text { bridge, long-span, isolation, compressible inclusion, integral frame } \\
\text { abutment, recycled TDA }\end{array}$ \\
\hline
\end{tabular}




\title{
Extending the application of integral frame abutment bridges in earthquake prone areas by using novel isolators of recycled materials
}

\author{
Stergios A Mitoulis ${ }^{1}$, Anastasia Palaiochorinou ${ }^{2}$, Ilias Georgiadis ${ }^{3}$ and \\ Sotiris Argyroudis ${ }^{2}$ \\ ${ }^{1}$ Department of Civil and Environmental Engineering, FEPS, University of Surrey, UK, \\ s.mitoulis@surrey.ac.uk,www.mitoulis.com \\ ${ }^{2}$ Department of Civil Engineering, Aristotle University of Thessaloniki, Greece \\ ${ }_{3}^{3}$ Projects Link Contracting Co L.L.C., Netherlands
}

\begin{abstract}
Integral Abutment Bridges (IABs) are jointless structures without bearings or expansion joints, which require minimum or zero maintenance. The barrier to the application of longspan IABs is the interaction of the abutment with the backfill soil during the thermal expansion and contraction of the bridge deck, i.e. serviceability, or when the bridge is subjected to dynamic loads, such as earthquakes. The interaction of the bridge with the backfill leads to settlements and ratcheting of the soil behind the abutment and, as a result, the soil pressures acting on the abutment build-up in the long-term. This paper provides a solution for the aforementioned challenges, by introducing a novel isolator that is a compressible inclusion (CI) of reused tyre derived aggregates (TDA) placed between the bridge abutment and the backfill. The compressibility of typical tyre derived aggregates was measured by laboratory tests and the compressible inclusion was designed accordingly. The CI was then applied to a typical integral frame abutment model, which was subjected to static and dynamic loads representing in-service and seismic loads correspondingly. The response of both the conventional and the isolated abutment was assessed based on the settlements of the backfill, the soil pressures and the actions of the abutment. The study of the isolated abutment showed that the achieved decoupling of the abutment from the backfill soil results in significant reductions of the settlements of the backfill and of the pressures acting on the abutment. Hence, the proposed research can be of use for extending the length limits of integral frame bridges subjected to earthquake excitations.
\end{abstract}

keywords: bridge; integral frame abutment; long-span; isolation; compressible inclusion

\section{INTRODUCTION}

Bridges are important infrastructure assets, which are costly to construct and maintain. Their maintenance is a major challenge in most developed countries and significant investment is required [1] to eliminate the bridge deficient backlog. Integral Abutment Bridges (IABs), whose piers and/or abutments are rigidly connected to the deck, are frame structures that have no bearings or expansion joints, which became popular recently [2][3], as they comply with the urgent requirement for maintenance-free bridges [4]. Hence, extending the length limits of IABs is a major challenge that was faced by researchers [5][6][7] as they can reduce costs and maintenance requirements [8].

The barriers to the evolution of integral bridges is the interaction of the abutment with the backfill soil, the deterioration of the latter, the excessive loading of the abutment and the 
deck, along with the lack of design provisions in the codes [9]. The aforementioned interaction is more challenging in longer bridges, as the abutment is subjected to large daily and seasonal movements by deck. The latter expands and contracts due to the temperature changes [10] [11], whilst in the long-term it exhibits a permanent shortening due to creep and shrinkage effects. Figure 1 shows qualitatively how the movements of the abutment evolve within 10 years, based on the effective bridge temperature as described by England et al. [12] and also the permanent shortening of the deck, due to prestressing, creep and shrinkage effects for a bridge of $120 \mathrm{~m}$ long. It is noted that the wing-walls are not connected to the abutment as they would increase significantly the stiffness of the abutment and thus restrain its flexural deflections. The cyclic movement of the abutment causes significant horizontal stress variations behind the abutments, build-up of the earth pressures [12][13][14][15] and nonlinear deflections of the backfill [16]. The significance of the earth pressures behind integral abutments and their evolution is further discussed by Barker et al. [17], Springman et al. [13] and other researchers [18] [19].

Ratcheting flow pattern [20], wedging and densification of the backfill, indicatively shown in Figure 1, cause gradual increase in the earth pressures, which eventually approach passive conditions [21]. Creep, prestressing and shrinkage of the deck cause considerable permanent dislocation of the abutment [22] towards the centre of the bridge. Settlements of the backfill, due to the consolidation of the soils and poor drainage [23], can potentially create a bump-at-the-end of the bridge, which creates unsafe driving conditions and discomfort. Additionally, cyclic thermal and permanent movements of the abutment, due to the creep and shrinkage of the deck, cause fatigue loading of the structural components of the abutment [24]. The aforementioned loads that act on the abutment are increased in long-span bridges and, in some cases, may exceed the ultimate shear or flexural capacity of the abutment [5]. Furthermore, dynamic effects, such as seismic loads, impose dynamic interaction [25] [26] effects, which deteriorate the performance and the integrity of the bridge. The aforementioned design challenges for IABs become considerably demanding when the length of the deck is increased.

In order to mitigate the aforementioned design issues, England [27] has patented a displacement compensation unit for integral bridges, Horvath [28] has introduced the use of expanded polystyrene and mechanically stabilised backfills to rectify the ratcheting effects and Hoppe [29] introduced the use of elasticised expanded polystyrene to alleviate interaction effects. Potzl et al. [30] tested full-height abutments with expanded polystyrene layers interjected between the abutment and the soil. However, it was found that the polystyrene exhibits permanent deformations and creeps [31], therefore gaps are being created between the abutment and the backfill, which allow the soil to flow. Loose soil, have been used by Arsoy et al. [24] as a means to enhance the resilience of the piles of stub-type abutments against repetitive cyclic loads. Humphrey et al. [32] [33] introduced the use of tyre derived aggregates as a compressible backfill soil for a rigid frame culvert to reduce the soil pressures on the walls.

This paper assesses the performance of an isolation scheme that mitigates the interaction of IABs with the backfill soil. The proposed isolation achieves decoupling of the bridge from the backfill soil and thus enables the design of longer IABs. For this purpose, novel compressible inclusions were studied and applied in model integral frame abutments, which are separated from a mechanically stabilised backfill. The compressible inclusion (CI) contains reused tyre derived aggregates (TDAs) and its properties were defined by laboratory tests. The Young's modulus, the permanent deformations and the behaviour of the CI were defined under repetitive loads, strictly for the design purposes of this study. The results were validated with available triaxial test results [34] [35]. Subsequently, the response of the abutment inclusions was investigated under thermal and dynamic loading through a 2D fully 
coupled finite element model in PLAXIS. The validation of the static and dynamic response of the model abutment was studied before [36]. The response of IABs was then evaluated on the basis of the earth pressures on the abutment, the permanent vertical displacements of the backfill soil and the actions on the abutment. It is noted that, the thermal and the permanent movements of the deck due to creep and shrinkage concern mainly the longitudinal direction of the bridge. Thus, this paper studied the response of the bridge in the longitudinal direction only.
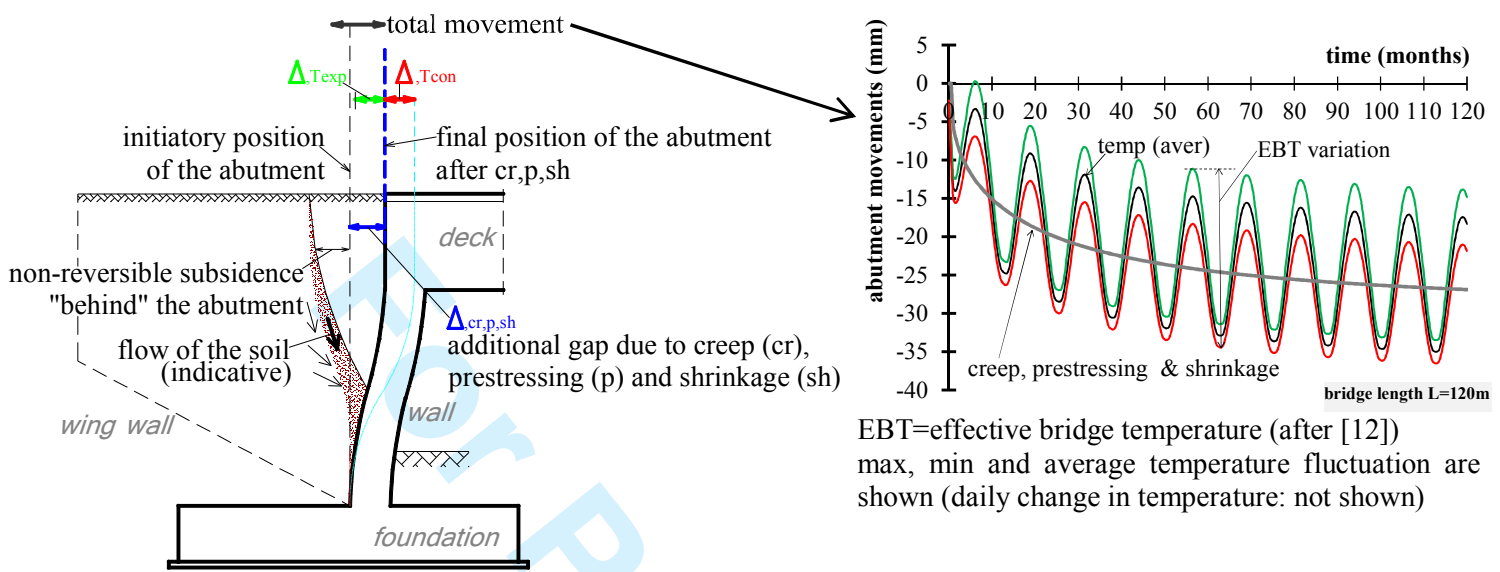

Figure 1. Left: initiatory and final position of the integral frame abutment (indicative). Right: the movements of the abutment due to the thermal expansion $\left(\Delta_{\text {,Texp }}\right)$ and contraction $(\Delta$, Tcon $)$ coupled with the permanent shortening of the deck $\left(\Delta_{\text {,cr,p,sh }}\right)$.

\section{DESCRIPTION OF THE INTEGRAL FRAME ABUTMENT AND THE BACKFILL SOIL}

\subsection{The typical and the proposed abutment with the compressible inclusion and the mechanically stabilised backfill}

A typical integral frame abutment with total height of $8.0 \mathrm{~m}$ was considered for this study, which is shown in Figure 2. The thickness of the wall was $1.0 \mathrm{~m}$ and the spread footing was $5.5 \mathrm{~m}$ long with a depth of $1.0 \mathrm{~m}$. The common stability checks of the abutment were performed and the design was found to meet the Eurocode requirements [37][38]. The depth of the foundation was $2.0 \mathrm{~m}$ from the ground surface. The selection of the shallow foundation was based upon the typical abutments geometries found in the international literature [14][39] and checked against realistic loads and displacements that were chosen based on conservative assumptions. The material of the abutment was concrete of class $\mathrm{C} 30 / 37$, unit weight 25.0 $\mathrm{kN} / \mathrm{m}^{3}$, Poisson's ratio 0.3 and Young's modulus $30 \mathrm{GPa}$. For all the analysis, a unit transverse width $(1.0 \mathrm{~m})$ of the abutment was considered. The abutment was rigidly connected to the deck. The latter had depth $1.6 \mathrm{~m}$, which corresponds to a typical bridge span of 35 to $45 \mathrm{~m}$ long, i.e. a typical span for prestressed concrete bridge decks. It was also assumed that the deck had considerable greater flexural stiffness than the abutment hence the top $1.5 \mathrm{~m}$ of the abutment was assumed to exhibit minimum rotations.

With regard to isolated abutment, shown in Figure $2 \mathrm{~b}$, two additional measures were considered, i.e. the compressible inclusion, comprising tyre derived aggregates, and the mechanically stabilised backfill. The aforementioned inclusion, i.e. the isolator, was a compressible layer was described in a previous study [36]. The isolator was placed vertically between the abutment wall and the backfill, as shown in Figure $2 b$. The backfill was 
reinforced by horizontal geogrid layers at $500 \mathrm{~mm}$ centres and length equal to the total height of the rigid frame abutment, i.e. $8.0 \mathrm{~m}$ to provide a mechanically stabilised earth. The filling material was considered to be compacted sand, while the foundation soil of both the typical and the proposed abutment was a clay material. The properties of the materials are given in the next sections.
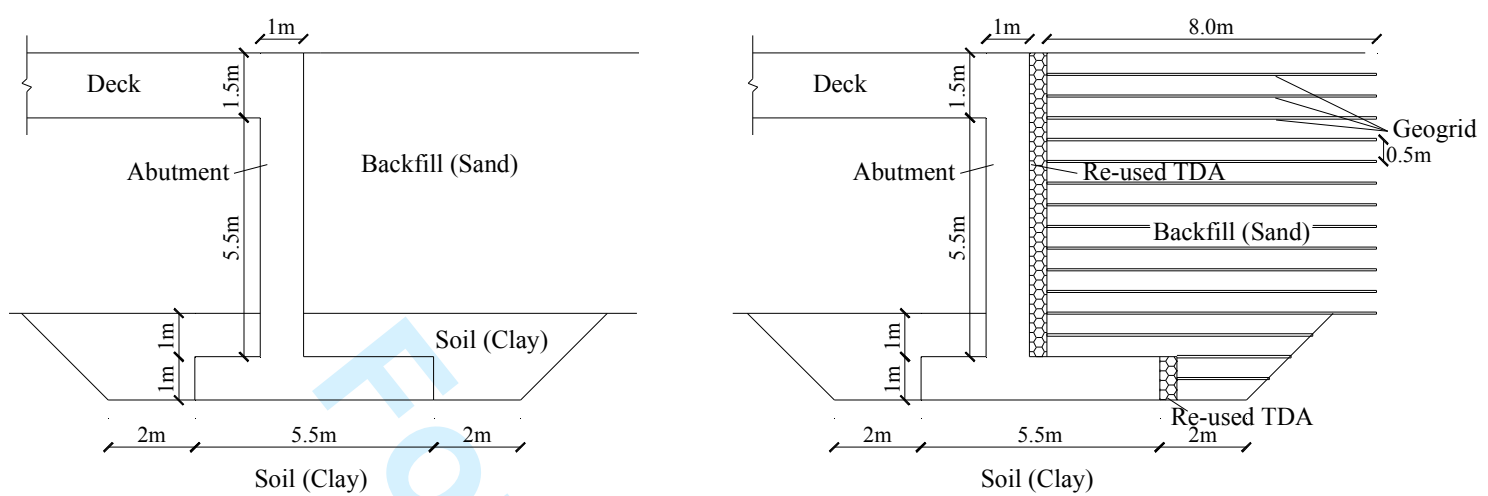

Figure 2. (a) Typical integral frame abutment and (b) the isolated abutment with the compressible inclusion of reused tyre derived aggregates (TDA) and the mechanically stabilised backfill.

\subsection{Properties of the compressible inclusion based on laboratory tests}

The mechanical properties of the compressible inclusion comprising tyre derived aggregates, were tested in the Laboratory of the University of Surrey, strictly for the design purposes of this research. The Young's modulus and the long-term behaviour of the inclusion under repetitive loads, i.e. the potential permanent deformations of the inclusion and the potential change in its compressibility were obtained. Different sizes of tyre derived aggregates and thicknesses of the CIs were also tested. A total of 42 different model CIs were tested under uniaxial loads. The properties obtained by the uniaxial tests were validated by triaxial tests conducted in Aristotle University [34] and were found in good agreement. Also, it was found that the CI exhibited negligible permanent deformations when subjected to 100 cycles of loading, whilst the hysteresis loops of the material under compression exhibited negligible variations during its cyclic loading, i.e. the stress-strain path remained unaltered throughout the tests. To account for the potential variability of the properties of the tyre derived material, different Poisson ratios ranging from 0.40 to 0.49 and different thicknesses of the compressible inclusion ranging from 100 to $300 \mathrm{~mm}$ were considered. The modulus of elasticity of the inclusion was found to be $56.9 \mathrm{kPa}$, which corresponds to a measured oedometric modulus of $\mathrm{E}_{\mathrm{oed}}=974.2 \mathrm{kPa}$. The unit weight of the tyre derived aggregates was $6.1 \mathrm{kN} / \mathrm{m}^{3}$. It is noted that the relatively high value of the Poisson ratio causes lateral deflections of the CI. However, these deflections are small and localised and do not affect the global response and integrity of the backfill or the abutment.

\subsection{Backfill and foundation soil properties}

A compacted sand was considered for the backfill with angle of friction of $42^{0}$ and dilatancy angle $10.9^{0}$. A soil deposit of $30 \mathrm{~m}$ depth corresponding to Eurocode 8 [40] ground type C was considered for the foundation soil. Both the backfill and foundation soil were assumed to have an elasto-plastic behavior and a Mohr-Coulomb criterion was considered. In order to account for the soil nonlinearity for the low to medium strain range, the parameters of the soil 
modulus and damping were estimated based on one dimensional equivalent linear analyses. Calibration followed in order to account for the dependency of both the stiffness and the damping on the strain level as per [41]. For higher strain levels the effect of nonlinearity was accounted for through the Mohr-Coulomb yield criterion that was used for the soil behaviour in the 2D numerical model. The soil properties are summarised in Table 1 . The geogrids used for stabilising the backfill had elastic behaviour with axial stiffness $E \cdot A=1.0 \mathrm{E}+05 \mathrm{kN} / \mathrm{m}$.

Table 1. Soil properties of the backfill and the foundation soil.

\begin{tabular}{|c|c|c|c|c|c|c|c|}
\hline & layer(s) & $\begin{array}{l}\text { thicknes } \\
\text { s z (m) }\end{array}$ & $\begin{array}{c}\text { weight } \\
\text { per } \mathbf{m}^{3} \\
\gamma \\
\left(\mathrm{kN} / \mathrm{m}^{3}\right)\end{array}$ & $\begin{array}{c}\text { Poisson' } \\
\text { s ratio } \\
\text { v } \\
\end{array}$ & $\begin{array}{c}\text { cohesio } \\
n \\
\text { c }(\mathbf{k P a})\end{array}$ & $\begin{array}{c}\text { modulus } \\
\text { of } \\
\text { elasticity } \\
\text { E (kPa) }\end{array}$ & $\begin{array}{c}\text { shear wave } \\
\text { velocity } \\
V_{\mathrm{s}}(\mathrm{m} / \mathrm{s})\end{array}$ \\
\hline $\begin{array}{c}\text { backfill } \\
\text { soil }\end{array}$ & $1-14$ & 0.5 & 18.5 & 0.43 & 0.01 & $3.89 \mathrm{E}+05$ & 268.4 \\
\hline \multirow{10}{*}{$\begin{array}{c}\text { foundation } \\
\text { soil }\end{array}$} & 1 & 3.0 & 19.0 & 0.35 & 50.0 & $1.69 \mathrm{E}+05$ & 179.9 \\
\hline & 2 & 3.0 & 19.0 & 0.35 & 78.5 & $2.31 \mathrm{E}+05$ & 209.9 \\
\hline & 3 & 3.0 & 19.0 & 0.35 & 92.8 & $2.65 \mathrm{E}+05$ & 224.9 \\
\hline & 4 & 3.0 & 19.0 & 0.35 & 107.0 & $3.01 \mathrm{E}+05$ & 239.9 \\
\hline & 5 & 3.0 & 19.0 & 0.35 & 121.3 & $3.40 \mathrm{E}+05$ & 254.9 \\
\hline & 6 & 3.0 & 19.0 & 0.35 & 135.5 & $3.67 \mathrm{E}+05$ & 264.9 \\
\hline & 7 & 3.0 & 19.0 & 0.35 & 149.8 & $4.10 \mathrm{E}+05$ & 279.9 \\
\hline & 8 & 3.0 & 19.0 & 0.35 & 164.0 & $4.40 \mathrm{E}+05$ & 289.9 \\
\hline & 9 & 3.0 & 19.0 & 0.35 & 178.3 & $4.71 \mathrm{E}+05$ & 299.8 \\
\hline & 10 & 3.0 & 19.0 & 0.35 & 192.5 & $5.03 \mathrm{E}+05$ & 309.8 \\
\hline
\end{tabular}

\section{NUMERICAL MODELLING AND PARAMETRIC ANALYSIS}

\subsection{Finite element model}

The coupled abutment-backfill analyses were performed with the plane strain finite element code PLAXIS 2D [42]. The model of the conventional structure comprises the abutment, the backfill and the foundation soil (Figure 4), while the isolated abutment also includes the compressible inclusion and the geogrids (Figure 5). The sequence of construction was given in [36]. The basis of the model was assumed as rigid and the lateral sides were absorbent to avoid boundary effects. The total width of the model was selected to be $180 \mathrm{~m}$, based on preliminary sensitivity analyses, which showed that this width is sufficient to minimise the boundary effects, without increasing significantly the computational cost. The discretisation of the model included a total number of 2299 15-node plane strain triangular elements. The backfill and the foundation are modeled with 14 and 10 layers respectively as shown in Figure 3. A rotational restraint with a beam element was inserted vertically and centrally in the top of the abutment cluster, to model the rotation restraint of the abutment top due to the stiff prestressed bridge deck. Also, the stiffness of the entire bridge system was taken into account by a horizontal fixed-end anchor element that was connected to the top of the abutment. The anchor was essentially a linear spring element that had axial stiffness of $\mathrm{E} \cdot \mathrm{A}=2.637 \mathrm{E}+7 \mathrm{kN}$. This value corresponded to the stiffness of an as-built bridge system described in [8] and represented a unit-length width of the bridge. The same bridge model was used later to reproduce a single-degree-of-freedom (SDOF) that was analysed to obtain the potential response of the bridge, which is induced at the abutment top. 
For the isolated abutment, geogrids were applied horizontally between the backfill layers, as well as vertically between the compressible inclusion and the backfill, as shown in Figure 5. For all the analyses, the initial geostatic stresses and the construction stages of the abutment, the backfill and the compressible inclusion were modelled to account for the initial stresses and the gradual loading of the components, as these stresses influence the long-term performance of the system [36]. Appropriate interface elements with a coefficient of $\mathrm{R}_{\text {inter }}=$ 0.70 were used to model the contact between the wall, the backfill and the foundation soil.

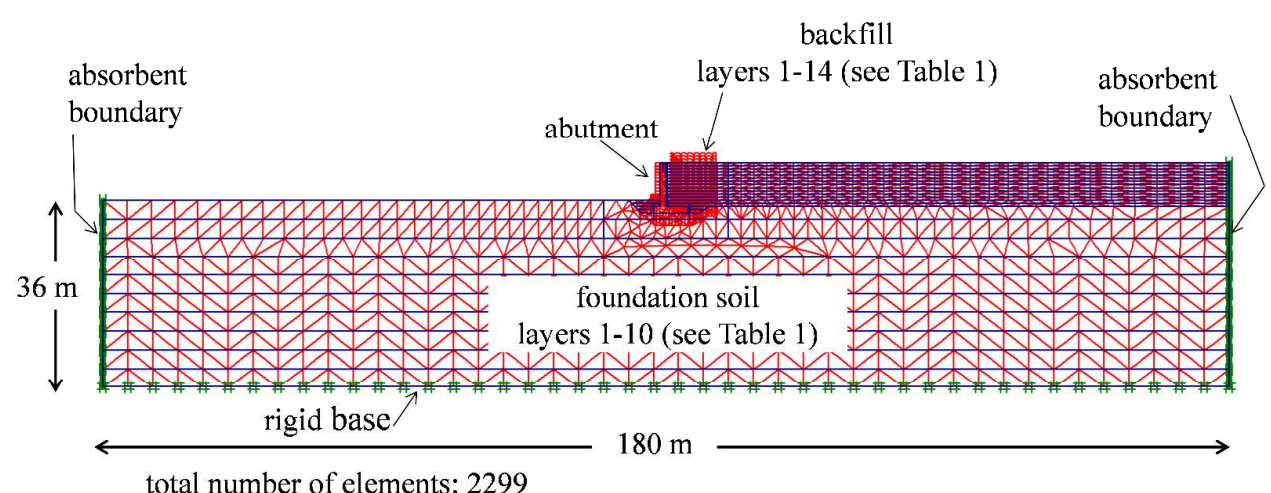

Figure 3. The 2D PLAXIS model of the proposed integral frame abutment with the compressible inclusion.

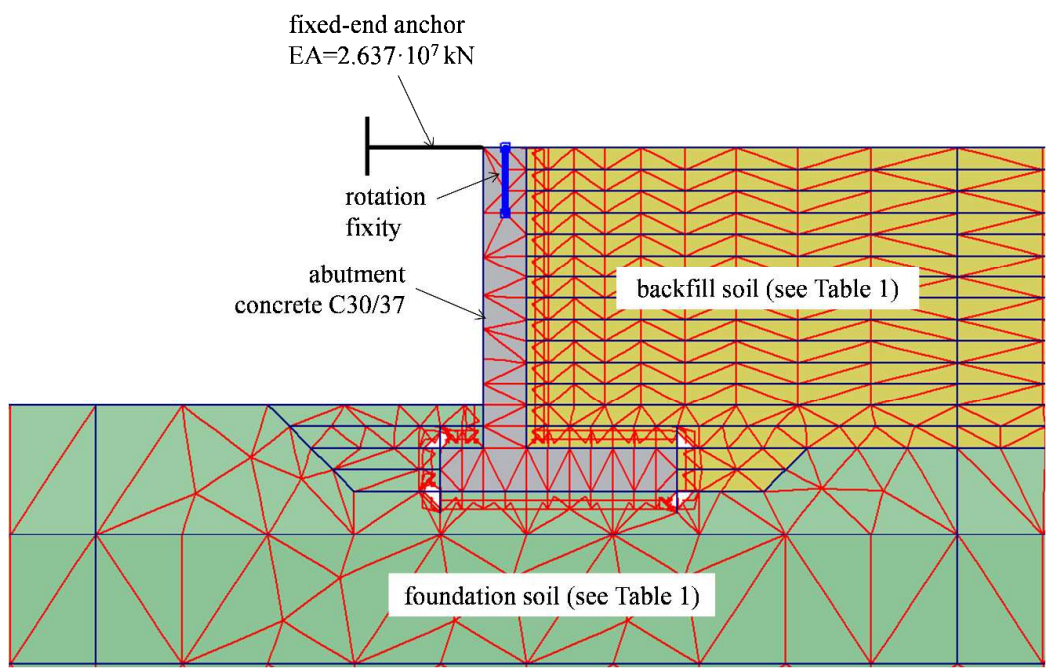

Figure 4. The model of the conventional integral abutment and the backfill soil.

\subsection{Temperature and seismic loads of abutments in long-span integral frame bridges}

Typical thermal cyclic and dynamic loads that act on abutments were considered. In particular, the thermal displacements of the deck were applied on the abutment, to model the expansion and contraction of the bridge. Also, dynamic seismic loads were introduced at the basis of the model, simultaneously with the response of the bridge deck, which induced an additional input motion acting on the abutment top. Subsequently, critical actions of the abutment and the backfill soil were compared for the conventional and the isolated system.

For the quasi-static cyclic loads due to thermal elongation or shortening of the deck, the abutment was considered to either push the backfill, during the expansion of the deck, or to move away from the backfill, when the deck contracted. The cyclic displacement of the abutment was considered to be $\pm 30 \mathrm{~mm}$, which is a common thermal displacement of bridges 


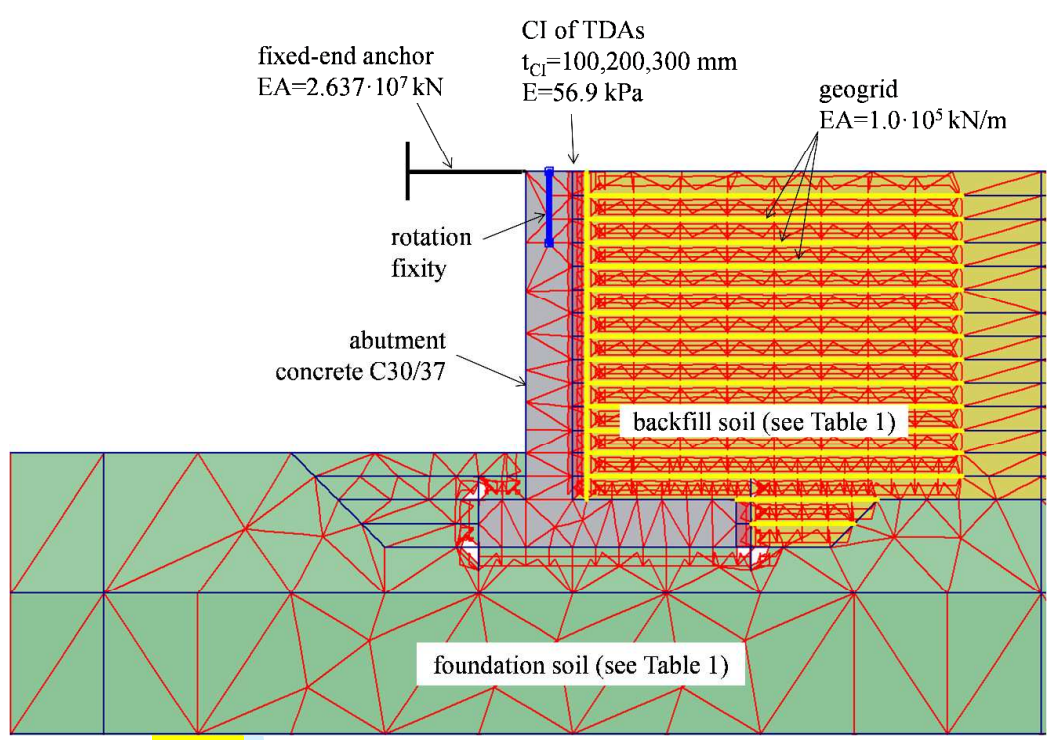

Figure 5. The integral frame abutment with the compressible inclusion and the mechanically stabilised backfill soil.

of 200-250 m long. The estimation of the displacement was based on a uniform temperature range of $\pm 25^{\circ} \mathrm{C}$ as per [43]. The variation of the thermal displacement did not account for the temperature gradients applied on the deck or the effects of prestressing, creep and shrinkage, which cause a permanent shortening of the deck and the dislocation of the abutment, as shown in Figure 1. Both the conventional and the proposed abutment models were subjected to one or ten cycles of thermal displacements to identify its short- and long-term behaviour respectively. The movement of $\pm 30 \mathrm{~mm}$ of the deck was applied as a uniform displacement along the top $1.5 \mathrm{~m}$ of the abutment. It is stressed that daily and seasonal temperature changes are random and hence cause random movements to the abutment [12]. For this particular study, it was assumed that the displacements of the abutment simulate the seasonal temperatures, as the daily variations are smaller and hence mobilise less significant interaction effects. The rate of the applied displacement was adequately small to minimise the inertia loads of the abutment and the backfill and, hence, achieve a quasi-static loading condition, which simulates the thermal movements of the deck.

It is noted that, based on a previous study [36], the behaviour of the abutment is significantly different when the abutment first pushes the backfill and subsequently moves away from it (i.e. expansion - contraction of the deck) or when the opposite occurs i.e. when the abutment first moves away from the fill -denoted here as "pull" condition- and subsequently pushes the backfill (i.e. contraction - expansion of the deck). To identify the effect of the two different interaction mechanisms, as per Figure 6 , both of the potential loading sequences were analysed.

With regard to dynamic loads, seven real earthquake motions (Table 2), scaled to $0.3 \mathrm{~g}$, were also analysed for both the conventional and the isolated abutment. All records were compliant with Eurocode 8-1 [40] elastic spectrum for ground type A as shown in Figure 7. A decoupling approach was followed to define the response of the abutment-backfill system due to both the seismic motion that is induced to the foundation of the abutment and the seismic response of the bridge deck.

Preliminary analyses were performed based on typical Ricker and sinusoidal pulses to obtain the dynamic characteristics of the abutment-backfill system. Both the stiffness and the damping of the system were estimated for different target displacements of the abutment and for various periods of the input motion ranging from 0.4 to $0.8 \mathrm{~s}$ as described in a previous 
study [44]. Subsequently, a set of single degree of freedom (SDOF) systems were analysed, which represented typical integral frame bridges with periods ranging from 0.4 to $0.8 \mathrm{~s}$. The dynamic analysis of the SDOF bridge models accounted for the stiffness, based on equations given by Mylonakis et al. [45], and the damping of the system abutment-backfill.

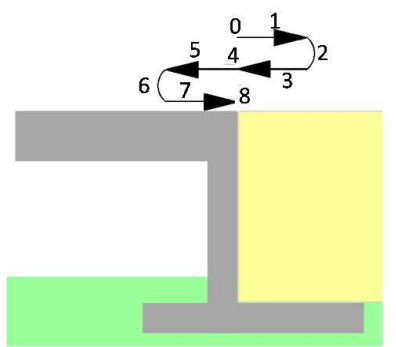

(a)

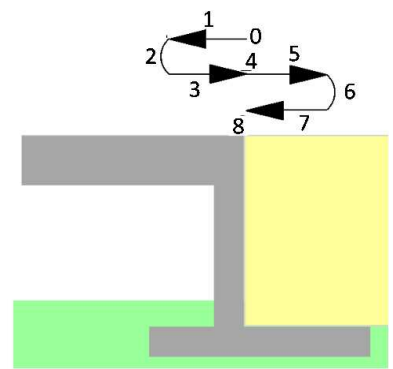

(b)

Figure 6 . The two loading conditions that were considered for the abutment (a) loading 1: push - pull and (b) loading 2: pull - push.

Table 2. Properties of the selected ground motions

\begin{tabular}{llcc}
\hline Earthquake name & Station ID - Station name & $\begin{array}{c}\text { Magnitude } \\
\mathrm{M}_{\mathrm{w}}\end{array}$ & $\begin{array}{c}\text { PGA } \\
(\mathrm{g})\end{array}$ \\
\hline Parnitha, Greece, 9/7/1999 & 2472-Athens 4 (Kipseli District) & 6.0 & 0.12 \\
Kozani, Greece, 5/13/1995 & ST1320 - Prefecture building & 6.5 & 0.14 \\
$\begin{array}{l}\text { Aigio, Greece, 6/15/1995 } \\
\text { Friuli, Italy, 5/6/1976 }\end{array}$ & Telecommunication building & 6.5 & 0.54 \\
$\begin{array}{l}\text { Montenegro, former } \\
\text { Yugoslavia, 4/15/1979 }\end{array}$ & ST64 & 6.4 & 0.32 \\
$\begin{array}{l}\text { Kern County, (Taft,) USA, } \\
\text { 7/21/1952 }\end{array}$ & Santa Barbara, Courthouse & 6.9 & 0.18 \\
Trinidad, USA, 8/24/1983 & 090 CDMG station 1498 & 7.3 & 0.20 \\
\hline
\end{tabular}

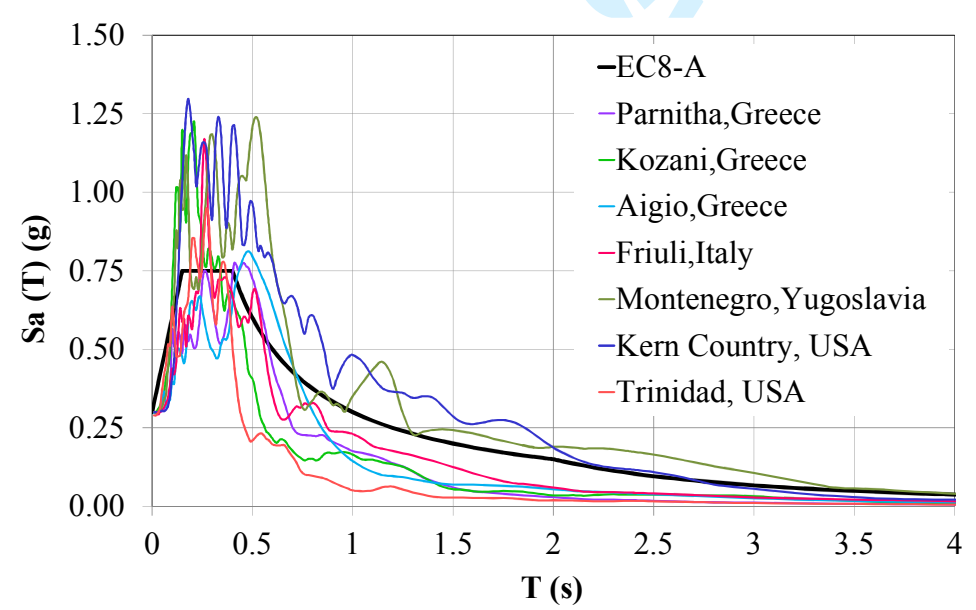

Figure 7. Elastic response spectra of the selected records and their mean spectra in correlation to the EC8-1 elastic response spectrum, all scaled to $0.3 \mathrm{~g}$.

The longitudinal response time history of the bridge (equivalent SDOF systems) obtained for each earthquake motion was used as an input to the top of the abutment in PLAXIS model. In particular, it was imposed as a force acting at the top of the abutment, simultaneously with the earthquake acceleration time history at the basis of the model. For 
simplicity, the seismic input motion and the response of the bridge deck, which was induced at the top of the abutment, were assumed to be coherent and synchronous. It is noted that, based on analyses, the response of the system abutment-backfill is mainly influenced by the input motion at the foundation, whilst the input motion of the bridge deck is less significant.

\section{RESULTS}

\subsection{Earth pressures on the integral frame abutment}

\section{Earth pressures on the abutment for the thermal movements of the deck}

Figure 8a shows the maximum pressures on the abutment corresponding to the maximum thermal movement of the deck $( \pm 30 \mathrm{~mm})$, shown on Figure 6 . The aforementioned movement was found to be received by the abutment as contraflexure (translational movement), and also caused rotation of the footing. The distribution of the stresses on the abutment is shown for loading conditions 1 and 2 for both abutment configurations, i.e. conventional (solid line) and isolated (dashed line) with the compressible inclusion (CI) and the mechanically stabilised earth (MSE). It was found that, the pressures on the isolated abutment were almost identical for both loading conditions, therefore, two coinciding dashed lines are shown for this case. The maximum pressure that was developed during one cycle of the movement of the isolated abutment due to the expansion and contraction of the deck was $43.0 \mathrm{kPa}$, which corresponds to pressures between active and at rest conditions. On the contrary, the pressures on the conventional abutment were significantly larger and reached passive conditions, with the maximum pressure reaching values of 528.8 and $692.0 \mathrm{kPa}$ for loading conditions 1 and 2 respectively. The maximum pressure was observed at a height equal to 3.0 to $3.5 \mathrm{~m}$ from the footing of the abutment, i.e. at a normalised height of 0.42 to 0.5 , when measured from the upper face of the surface footing. It is also observed that the soil pressure diagrams of the conventional abutment, exhibit cusps and drops, which was due to the yielding of the soil. In particular, cusps and drops were at the failure surfaces of the backfill. No yielding of the backfill soil was observed in the case of the isolated abutment. The latter finding indicates that the pressures are kept low and the backfill soil was not disturbed by the moving abutment, when the latter was isolated from the mechanically stabilised backfill.

The results were somewhat different when a total of ten full cycles of deck movements $( \pm 30 \mathrm{~mm})$ were applied on the abutment (Figure $8 \mathrm{~b}$ ). In this case the isolated abutment exhibits a maximum earth pressure of $100 \mathrm{kPa}$, close to the footing, as opposed to the 465.2 $\mathrm{kPa}$ of pressure that was developed on the conventional abutment. For this particular comparison supplementary analyses were performed considering that the conventional backfill soil is reinforced, but no CI was used. The aim of the additional analyses was to identify the influence of the soil reinforcement and the CI on the abutment pressures. The analyses showed that the pressures are drastically reduced from $465.2 \mathrm{kPa}$ to $140 \mathrm{kPa}$ when the backfill soil is reinforced; however the presence of the CI is an additional measure that further reduces these pressures. It is also worth noting that the variation of the properties of the elastomeric material was negligible for the different types of tyre derived aggregates that had Poisson's ratios ranging from 0.4 to 0.49 . Therefore, the results presented in this paper will only refer to elastomers that form a CI with Poisson's ratio 0.49 .

The results also showed that there is a negligible influence of the thickness of the CI on the profile of the soil pressures. Figure $9 \mathrm{a}$ illustrates the distribution of the maximum observed soil pressures along the height of the isolated abutment for loading pattern 1 (i.e. push-pull conditions) for different thicknesses of the inclusion. It is observed that the effect is negligible at the bottom of the abutment $(1.0$ to $6.0 \mathrm{~m})$, whilst the soil pressures are slightly 
influenced at the abutment top, i.e. at the level of the bridge deck, where the maximum displacements were observed. In particular, it was found that the soil pressures at the top of the abutment were reduced by $20 \%$ when the thickness of the CI was increased from 100 to $300 \mathrm{~mm}$. However, the stresses were kept at very low values, i.e. 2 to $10 \mathrm{kPa}$ and hence are considered to be negligible. This is also shown on the top right detail of Figure 9a. In all the cases analysed it was found that the larger the thickness of the CI the lower the soil pressures.

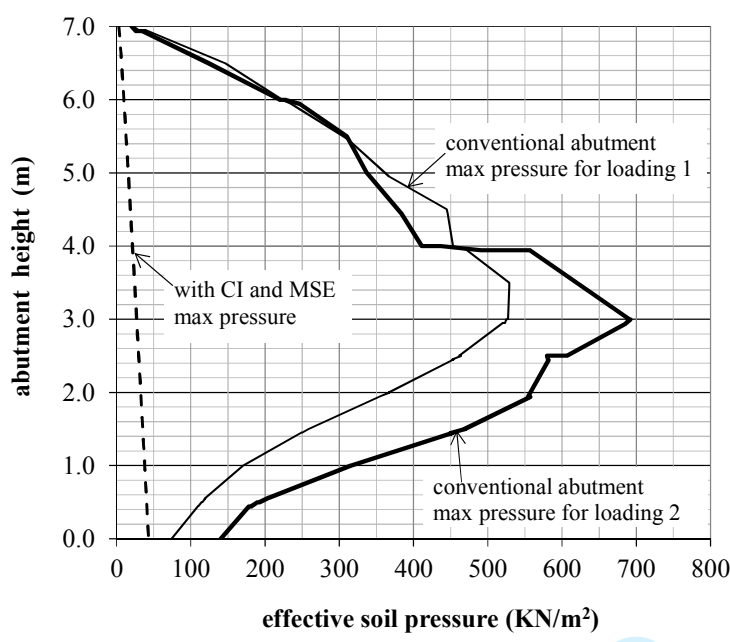

(a)

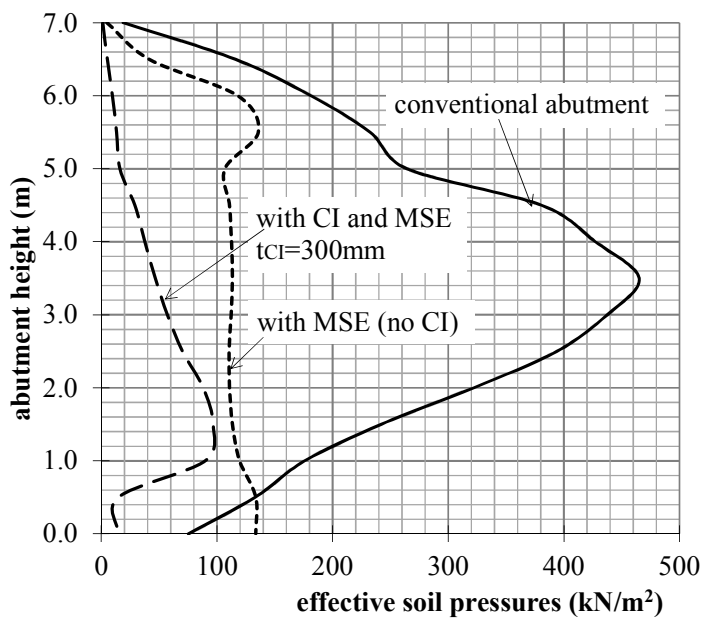

(b)

Figure 8. Maximum pressures acting on the conventional and the isolated abutment (thickness of the $\mathrm{CI} \mathrm{t}_{\mathrm{Cl}}=300 \mathrm{~mm}$ ) when the deck expands and contracts under maximum uniform temperatures: (a) one full cycle of loading and (b) ten full cycles.

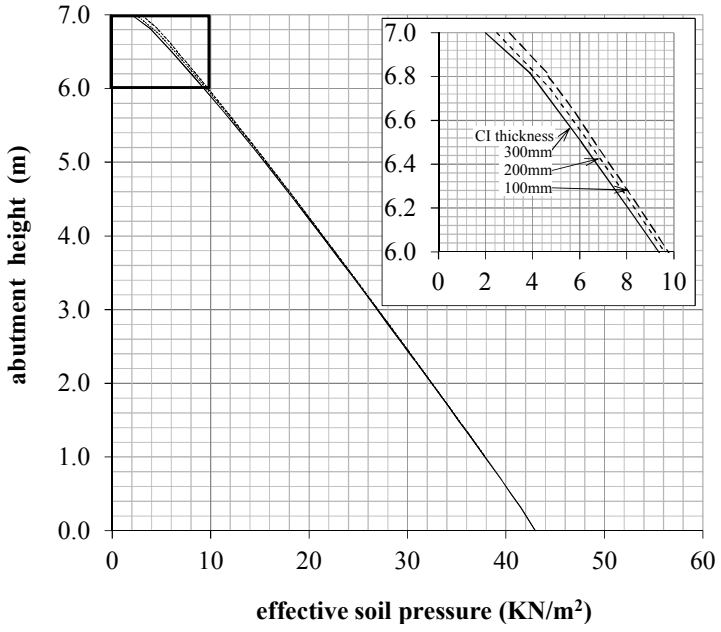

(a)

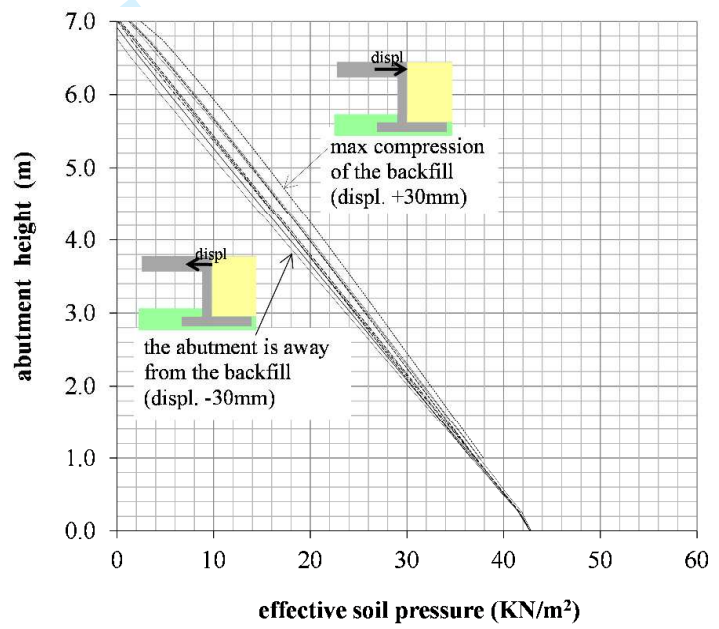

(b)

Figure 9. (a) The maximum soil pressures on the isolated abutment for different thicknesses of the compressible inclusion and on the top right: soil pressures for height 6 to $7 \mathrm{~m}$ (area indicated in the top left), (b) pressures on the abutment for loading stages 0 to 8 of loading pattern 1 (push-pull).

It is also worth noticing that the distribution of pressures acting on the isolated abutment did not vary significantly during the cyclic loading, as it shown in Figure 9b. The abutment has the initiatory position (step 0 ), then it is displaced due to the maximum expansion of the deck by $30 \mathrm{~mm}$ towards the backfill soil (steps 1 and 2) and then moves away from the backfill soil during the maximum contraction of the deck (steps 4, 5 and 6) and subsequently 
returns to its original position (steps 7 and 8 as per Figure 6). Figure $9 \mathrm{~b}$ shows that the variation of the soil pressures is negligible throughout the loading for the isolated abutment. Also, the distribution of stresses along the height of the abutment is essentially linear. On the contrary, when the abutment is in contact with the backfill, the earth pressures exhibited a significant variation along the height of the abutment, as shown before [46]. Additionally, the distribution of stresses, along the height of conventional abutments, is not linear. Hence, the isolation of the abutment by making use of the compressible inclusion reduces significantly the soil pressures and hence can be used for the cost-effective design of the abutment.

\section{Earth pressures on the abutment for dynamic loads}

Prior to the analysis of the abutment for earthquake excitations, it was considered essential to assess the dynamic characteristics of the coupled system (bridge-abutment-backfill) for sinusoidal pulses that had periods, which were close to the period of the system. Based on previous studies [44] sinusoidal pulses of periods 0.3 and $0.5 \mathrm{~s}$ were analysed. Table 3 shows a summary of the results obtained from this analysis. It is noted that the fundamental period of the conventional abutment was approximately $0.5 \mathrm{~s}$. As a result, both the relative displacements and the soil pressures are maximised for the sinusoidal input motion of period $0.5 \mathrm{~s}$. The aforementioned relative displacements, i.e. displacement of abutment top minus displacement at abutment bottom, provide an indication of the abutment deformation, i.e. whether the displacement is translational or rotational. The table also shows that the relative displacements of the conventional abutment are 15 and $25 \mathrm{~mm}$ for the periods of 0.3 and 0.5 sec correspondingly. The displacements were found to be significantly larger when the abutment is isolated, i.e. when the CI was considered. Indicatively, the maximum relative displacement reached, was 65,43 or $48 \mathrm{~mm}$ when a CI of 100,200 or $300 \mathrm{~mm}$ thick was considered respectively. On the contrary, the earth pressures were considerably reduced when the abutment was isolated by the backfill. Indicatively, the maximum effective pressure was $520.3 \mathrm{kPa}$ for the conventional abutment and $65.6,56.5$ and $53.8 \mathrm{kPa}$ when the CIs of 100 , 200 and $300 \mathrm{~mm}$ of thickness were used. The efficiency of the compressible inclusion with regard to achieved isolation of the abutment was further assessed on the basis of real seismic ground motions.

Table 3. The relative displacements of the abutments for the sinusoidal input motions and the maximum effective soil pressure on the abutment.

\begin{tabular}{ccccccccc}
\hline & \multicolumn{1}{c}{ conventional } & \multicolumn{2}{c}{ isolated } & $\mathrm{t}_{\mathrm{Cl}}=200 \mathrm{~mm}$ & $\mathrm{t}_{\mathrm{Cl}}=300 \mathrm{~mm}$ \\
\cline { 2 - 8 } $\begin{array}{c}\text { load case } \\
\text { period } \\
(\mathrm{sec})\end{array}$ & $\begin{array}{c}\text { max } \\
\text { displac. } \\
(\mathrm{mm})\end{array}$ & $\begin{array}{c}\text { max eff. } \\
\text { pressure } \\
(\mathrm{kPa})\end{array}$ & $\begin{array}{c}\text { max } \\
\text { displac. } \\
(\mathrm{mm})\end{array}$ & $\begin{array}{c}\text { max eff. } \\
\text { pressure } \\
(\mathrm{kPa})\end{array}$ & $\begin{array}{c}\text { max } \\
\text { displac. } \\
(\mathrm{mm})\end{array}$ & $\begin{array}{c}\text { max eff. } \\
\text { pressure } \\
(\mathrm{kPa})\end{array}$ & $\begin{array}{c}\text { max } \\
\text { displac. } \\
(\mathrm{mm})\end{array}$ & $\begin{array}{c}\text { max eff. } \\
\text { pressure } \\
(\mathrm{kPa})\end{array}$ \\
\hline $\begin{array}{c}\text { sinusoidal } \\
0.3 \mathrm{~s}\end{array}$ & 19 & 343.0 & 24 & 44.7 & 23 & 44.1 & 23 & 43.6 \\
\hline $\begin{array}{c}\text { sinusoidal } \\
0.5 \mathrm{~s}\end{array}$ & 34 & 520.3 & 65 & 65.6 & 43 & 56.5 & 48 & 53.8 \\
\hline
\end{tabular}

Figure $10 \mathrm{a}$ and $\mathrm{b}$ show the permanent earth pressures acting on both the conventional (solid lines) and the isolated abutment (dashed lines), when the systems were subjected to the seismic motions of Parnitha and Kern County, scaled to $0.3 \mathrm{~g}$, as per Table 2 and Figure 7. Figure 10a shows that the permanent pressures on the conventional abutment can be as high as $230.2 \mathrm{kPa}$, whereas the maximum pressure that was observed for the abutment with the CI 
of $300 \mathrm{~mm}$ was $42.7 \mathrm{kPa}$, i.e. approximately one fifth of the estimated pressures acting upon the conventional one. The soil pressures for the Kern County ground motion were found to be $400.6 \mathrm{kPa}$ and $60.2 \mathrm{kPa}$ for the conventional and the isolated abutment respectively, which, again, indicates an efficient reduction of the pressures for the latter.

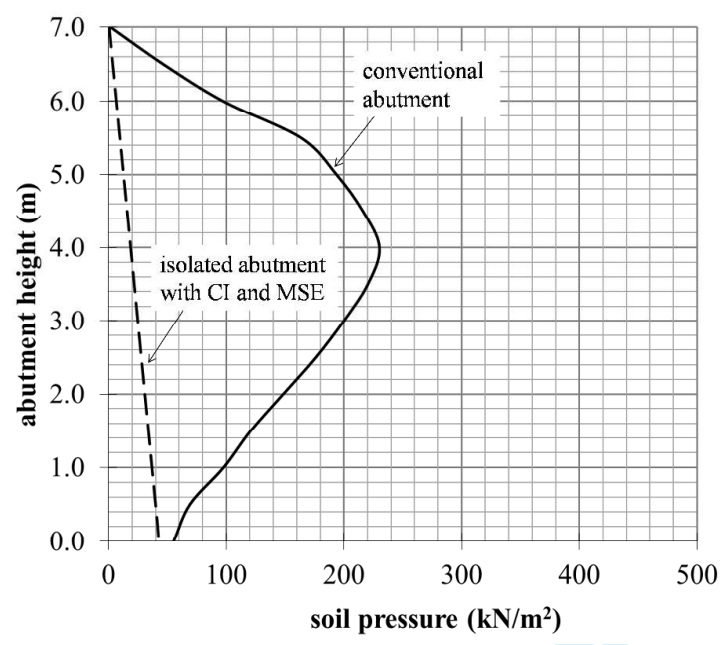

(a)

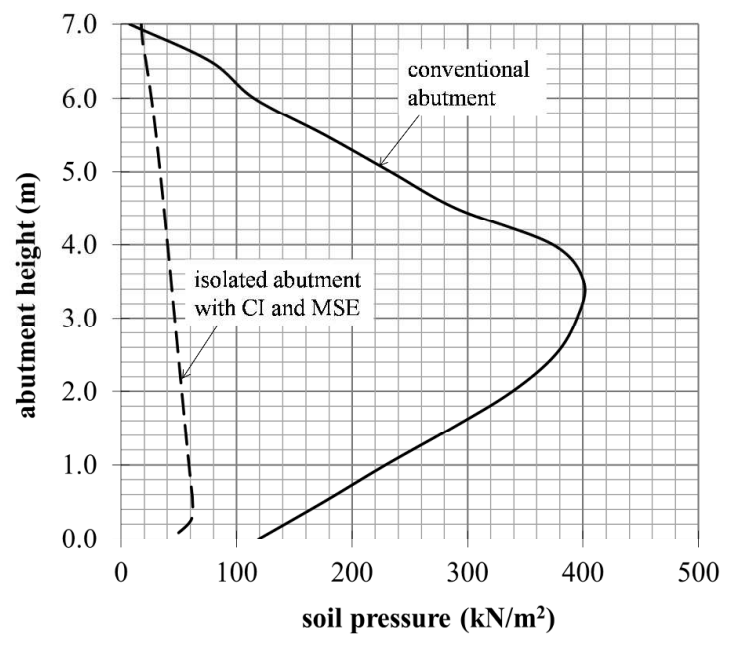

(b)

Figure 10 The permanent (post-earthquake) soil pressures on the abutment for the ground motions of (a) Parnitha and (b) Kern County.

Figure 11 summarises the soil pressures acting on the model abutments during and after the model abutments were subjected to the seven diverse ground motions. The solid lines correspond to the profile of the pressures on the conventional, whilst the dashed lines represent the pressures acting on the isolated abutment. The mean value and the standard deviation of the pressures calculated for the seven ground motions are shown. In particular,

Figure 11a shows the maximum recorded pressures on the abutment during the earthquake excitation, whilst Figure $11 \mathrm{~b}$ shows the remainder pressures after the seismic loading of the model abutments. Based on Figure 11a, the soil pressures on the abutment may vary significantly along the height of the conventional abutment. The analysis also showed that the conventional abutment receives mean pressure of $333.2 \pm 160.4 \mathrm{kPa}$, where $\pm 160.4 \mathrm{kPa}$ is the standard deviation, whilst the soil pressure developed on the isolated abutment was $147.7 \pm 91.0 \mathrm{kPa}$. Hence, the coefficient of earth pressures during earthquake reached passive values ranging between 1.9 to 8.8 with a mean value of 5.9 for the conventional abutment, whilst it ranged between 0.5 to 2.8 with a mean value of 1.4 for the isolated abutment. Additionally, the resultant force that was produced by the backfill soil against the abutment was $1580.8 \mathrm{kN}$ for the conventional and $536.0 \mathrm{kN}$ for the isolated abutment. Hence, the isolation of the abutment with the proposed CI reduces effectively the pressures on the abutment, as the maximum stresses developed and the resultant force that acts on the abutment are reduced. Also, significant reduction of the coefficient of earth pressures was also achieved for the isolated abutment, it was found to be almost one fourth (1/4) of the value obtained for the conventional one.

Based on Figure $11 \mathrm{~b}$, the remainder post-earthquake pressure on the conventional abutment is $190.4 \pm 107.9 \mathrm{kPa}$, whilst the isolated abutment receives a maximum pressure of $46.9 \pm 7.9 \mathrm{kPa}$. Additionally, the distribution of stresses is significantly different for the conventional and the isolated abutment. In particular, the resultant force of $917.1 \mathrm{kN}$ of the conventional abutment is applied at $3.17 \mathrm{~m}$, i.e. at $45 \%$ of the height of the abutment, whereas the distribution of the soil pressures on the isolated abutment follows a linear, almost 
triangular, distribution and the resultant force on the abutment was $191.9 \mathrm{kN}$. Notably, the pressures on the isolated abutment were found to correspond to pressures between the active and those at rest state, as opposed to the pressures on the conventional abutment, on which passive pressures were developed. In particular, the coefficient of the passive soil pressures was found to reach a maximum of 6.0 , when the seven different input motions were applied on the conventional abutment. On the contrary, the coefficient of earth pressures acting on the isolated abutment was well below 1.0, indicating that active state pressures are applied on the abutment at the aftermath of severe dynamic loads.

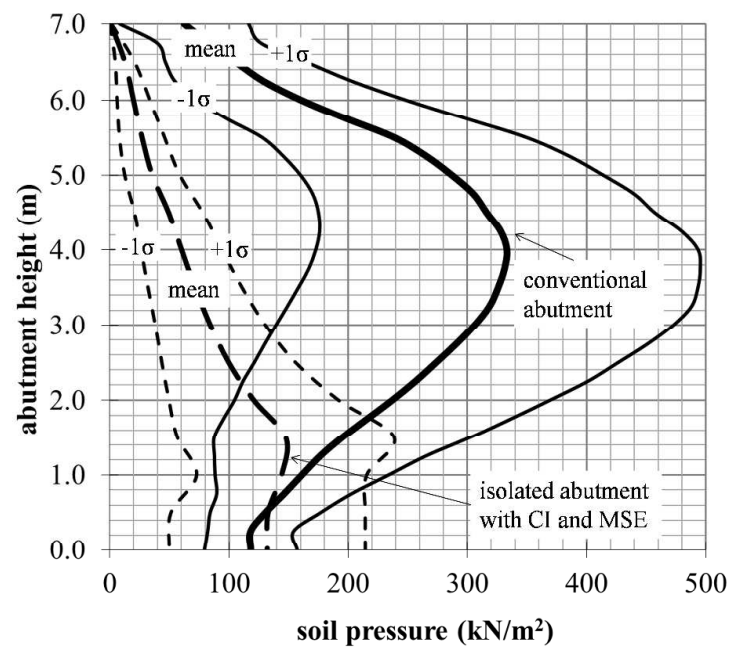

(a)

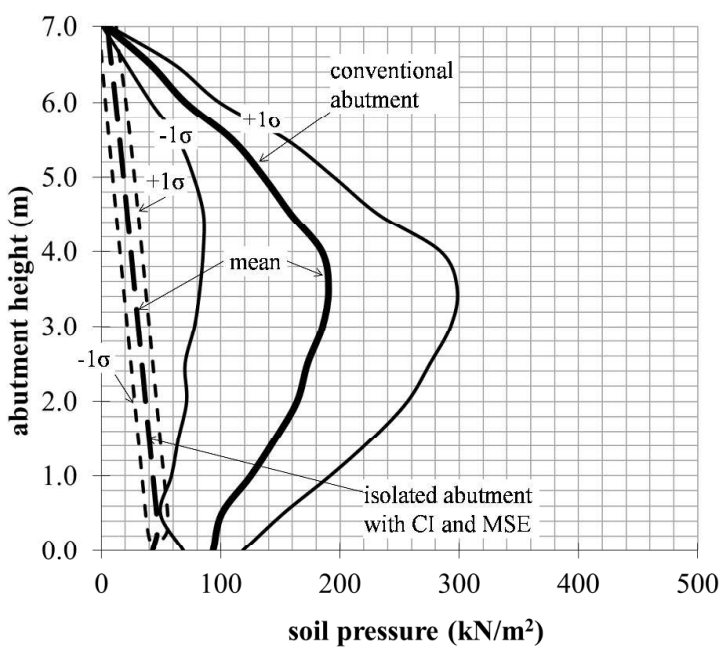

(b)

Figure 11. The soil pressures acting on the abutments: (a) maximum during the earthquake, (b) permanent at the end of the earthquake. (The figures show the mean values and the standard deviation of estimated pressures based on the seven ground motions).

\subsection{Permanent vertical displacements of the backfill soil}

\section{Permanent vertical displacements under thermal expansion and contraction of the deck}

As it was mentioned before, a design challenge for integral abutment bridges is the permanent deformation of the backfill, which undermines the integrity of the abutment and the bridge in the long term. These deflections are either settlements or swelling of the backfill, which are not reversible, due to the non-linear behaviour of the soil. In this regard, the permanent deformation of the backfill soil was assessed for the conventional and the isolated abutment. It is noted that small permanent vertical deflections of the backfill soil may be accommodated by designing the approach slab that will be simply supported between two ends and leaving a vertical gap between the slab and the backfill.

Figure $12 \mathrm{a}$ and $\mathrm{b}$ show the permanent vertical displacements of the backfill soil after one full cycle of loading patterns 1 and 2 correspondingly, for both the conventional and isolated abutments. The figures show that the isolated abutment has negligible permanent vertical deflections. The conventional backfill exhibited a maximum of $24 \mathrm{~mm}$ and $21 \mathrm{~mm}$ of settlement for loading conditions 1 and 2 correspondingly. Additionally, the backfill soil behind the conventional abutment exhibited swelling, with loading 2 causing a maximum of 8 $\mathrm{mm}$ of swelling at a distance of 2.5 to $3.0 \mathrm{~m}$ from the abutment. It is worth mentioning that the isolation of the footing, as shown in Figure $2 b$ was found to be crucial for the settlements of the isolated abutment, as the interaction between the footing and the backfill soil "behind" the foundation can trigger settlements of the soil. 
The effective reduction of the backfill vertical deflections showed in Figure $12 \mathrm{a}$ and $\mathrm{b}$ is interpreted by Figure 13, which shows the maximum horizontal displacements for the conventional and the isolated abutment at the maximum expansion of $+30 \mathrm{~mm}$. Figure $13 \mathrm{a}$ shows that, for the case of the conventional abutment, the displacements directly affect the backfill soil and as a result the soil deflects by $+30 \mathrm{~mm}$ at the top. Also, the imposition of this displacement affects a relatively large length of the backfill that is $12 \mathrm{~m}$ long. On the contrary, the backfill soil is not significantly deflected when the isolated abutment moves towards it. The maximum stress that was developed in the CI was $155 \mathrm{kPa}$. As a result, the backfill soil remains almost undisturbed and hence exhibits negligible horizontal deflections, and therefore small settlements, as shown in Figure 12. Additionally, the horizontal displacements of the backfill for different thicknesses of the CI did not differ significantly.

To identify the long-term deflection of the backfill, the numerical models were subjected to a total of ten thermal cycles as per Figure 6 . Figure 14a shows that the backfill behind the conventional abutment has a maximum settlement of $85 \mathrm{~mm}$, followed by a permanent swelling of $115 \mathrm{~mm}$, for loading pattern 1. The isolated abutment was found to have less significant interaction with the backfill soil, as the maximum soil swelling observed behind the abutment was $15 \mathrm{~mm}$, whilst the maximum settlement of $65 \mathrm{~mm}$ was observed away from the abutment, i.e. at a distance of $8.0 \mathrm{~m}$ from the abutment. Figure $14 \mathrm{~b}$ shows that the maximum settlement and swelling of the soil behind the conventional abutment were $80 \mathrm{~mm}$ and $124 \mathrm{~mm}$ correspondingly, for loading pattern 2 . Therefore, the response of the backfill soil is not expected to be significantly influenced by the loading pattern in the long term. Moreover, the isolated abutment achieved a significant mitigation of the settlements, especially for the first three metres behind the abutment that are important, due to the prospected formation of bumps and the potential cracking of the approach slab. Hence, it is expected that the long-term performance of isolated abutments will require less maintenance, i.e. replacement of the approach slab and/or the backfill soil.

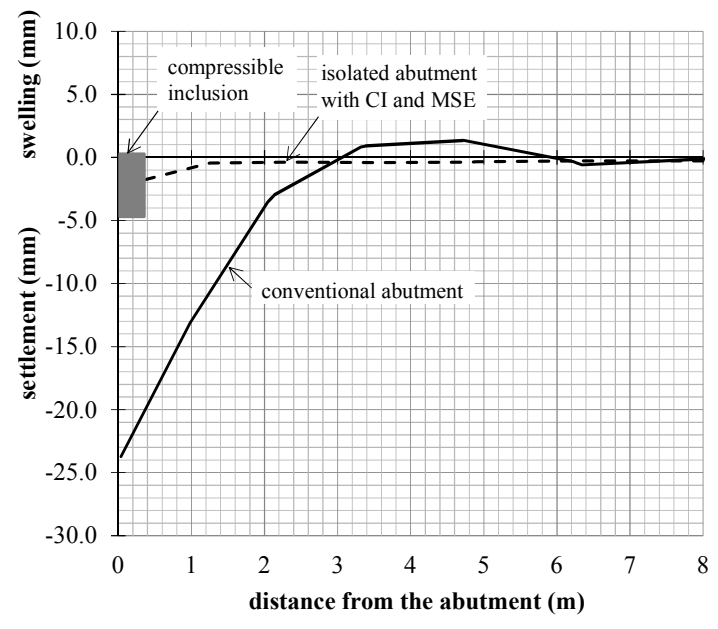

(a)

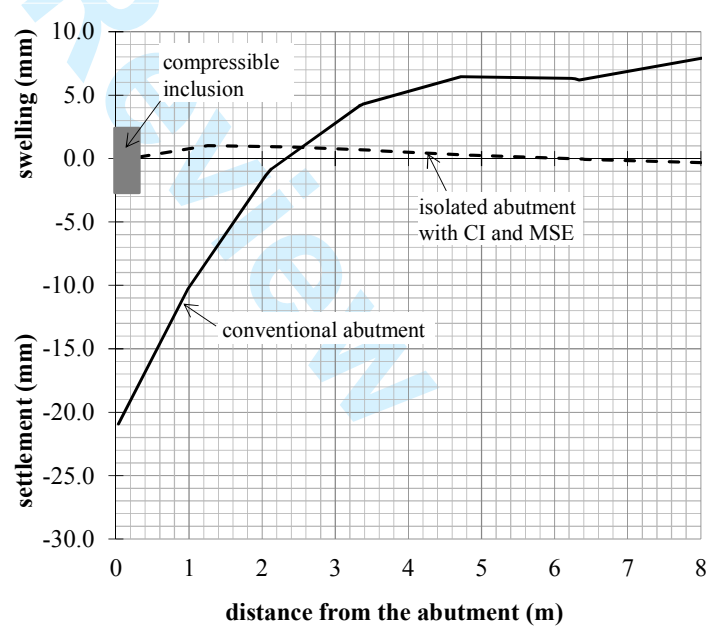

(b)

Figure 12. The swelling and the settlements of the backfill soil after one full cycle of (a) loading pattern 1 (push-pull) and (b) loading pattern 2 (pull-push). 


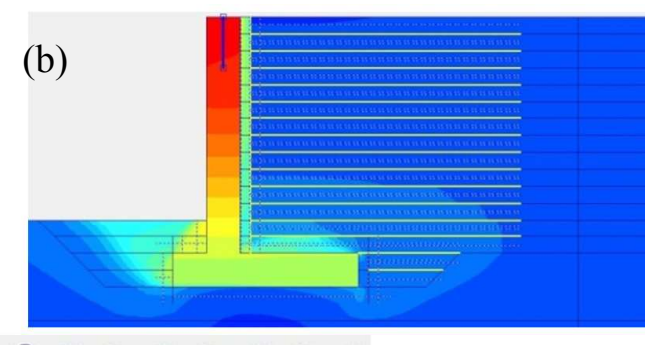

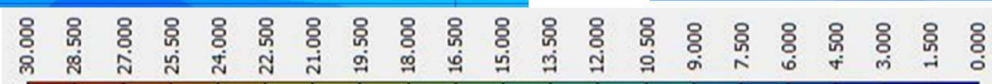
(unit: $\mathrm{mm}$ )

Figure 13. The horizontal displacements of the abutment and the backfill soil during the maximum expansion of the deck $(+30 \mathrm{~mm})$ for the (a) conventional and (b) the isolated abutment.

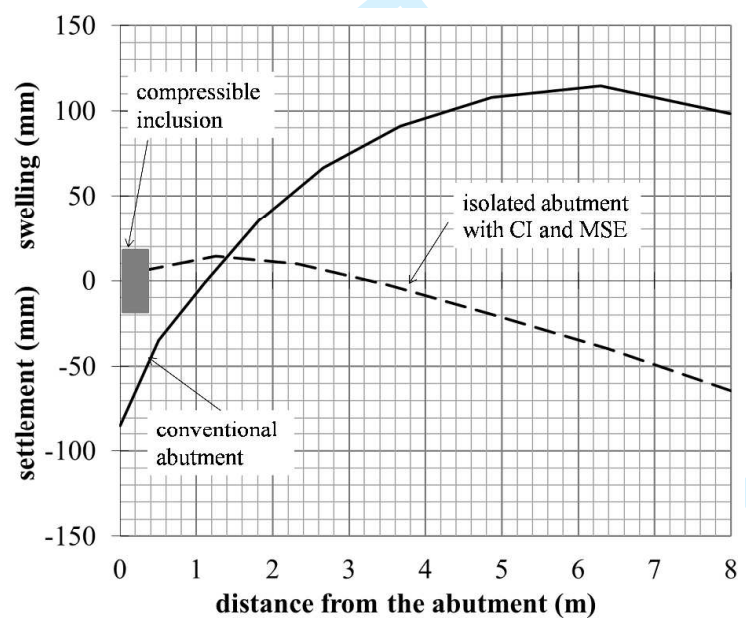

(a)

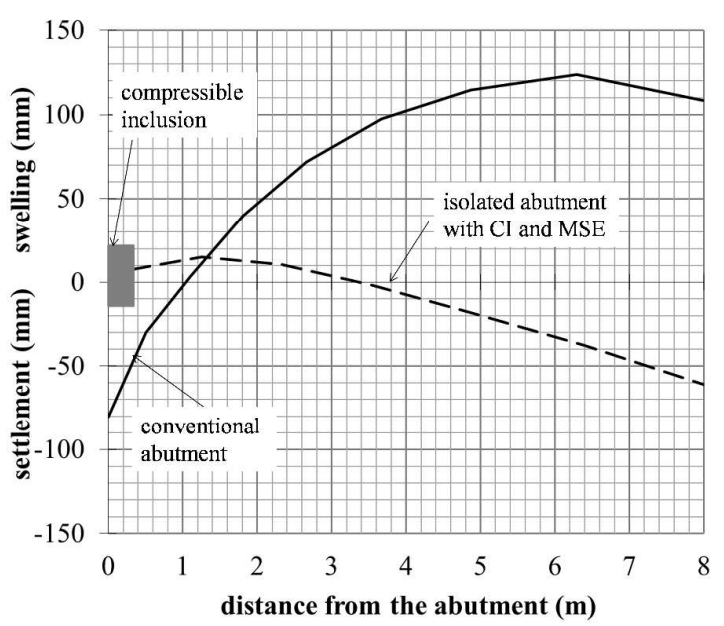

(b)

Figure 14. The deflection of the backfill soil after ten cycles of maximum thermal movements of the deck ( $\pm 30 \mathrm{~mm}$ ) for (a) loading 1 (push-pull) and (b) loading 2 (pull-push).

\section{Permanent vertical displacements under earthquake excitations}

Figure 15a and $\mathrm{b}$ show the permanent vertical displacements of the backfill soil after the Friuli and Montenegro earthquake motion correspondingly. The vertical deflections of the backfill were either a permanent recession of the soil downwards or swelling upwards. It was observed that the abutment with the compressible inclusion and the mechanically stabilised fill exhibited maximum settlements of $14 \mathrm{~mm}$ for both earthquake motions. The conventional backfill exhibited maximum settlements of 50 and $75 \mathrm{~mm}$, for the Friuli and the Montenegro ground motion correspondingly and the affected lengths of 3 to $1.5 \mathrm{~m}$ behind the abutment respectively. After this transition zone the backfill exhibited either negligible settlements (Friuli) or maximum swelling of $47 \mathrm{~mm}$ (Montenegro).

It was evident throughout the analyses that the settlements and the swelling of the backfill soil varied significantly when the coupled system was subjected to different earthquake excitations. Results are summarised in Figure 16a, which shows the mean value and mean $\pm 1 \sigma$ standard deviation of permanent, i.e. post-earthquake, vertical deflections of the backfill for the conventional (solid lines) and the isolated abutment (dashed line). The figure shows that the backfill behind the conventional abutment responds with settlements in the range of 8.0 to $79.0 \mathrm{~mm}$. At larger distances from the abutment the soil exhibited either settlements or swelling, with the latter having being maximised at a distance 4.0 to $5.0 \mathrm{~m}$ from the abutment 
as it is also illustrated in Figure 16b. In average, the permanent deflection of the backfill soil was found to be either a deflection of $57 \mathrm{~mm}$ upwards or a settlement of $17 \mathrm{~mm}$. On the contrary, the backfill of the isolated abutment exhibited negligible settlements, as shown with the dashed lines in Figure 16a.

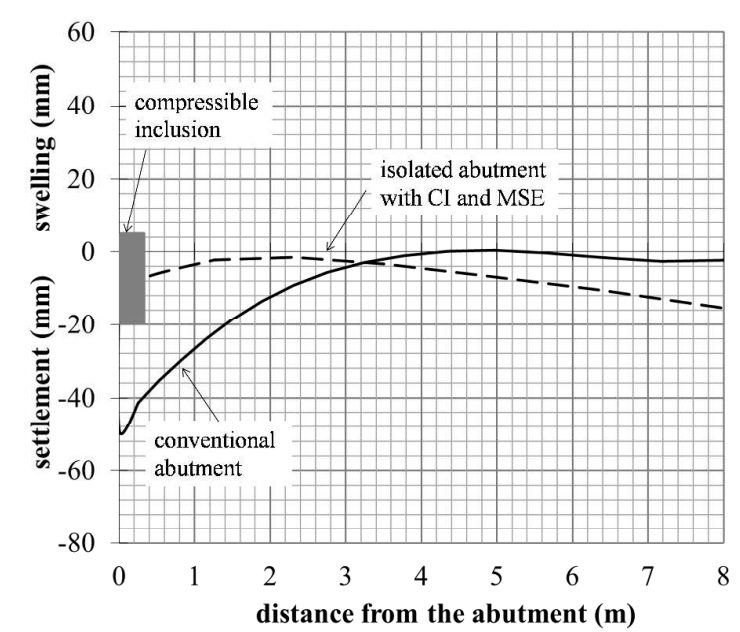

(a)

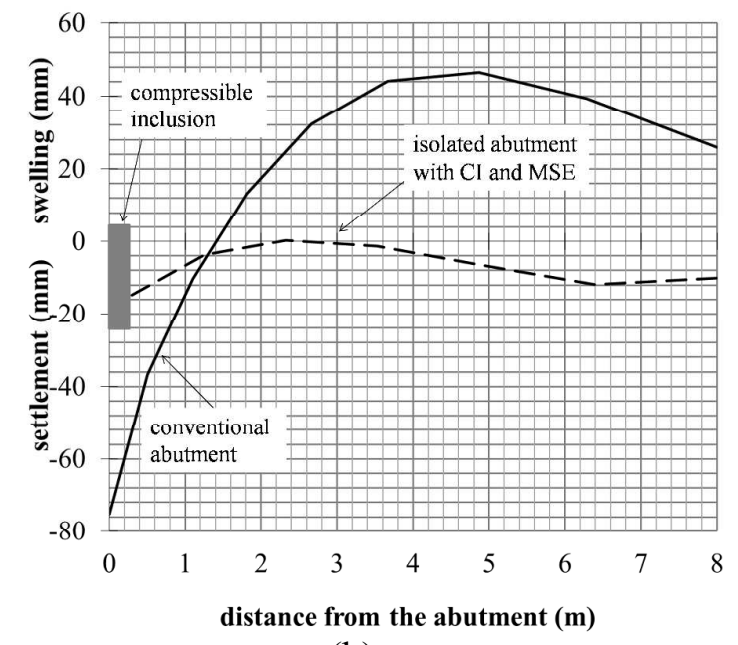

(b)

Figure 15. The settlements and the swelling of the backfill soil after the (a) Friuli and the (b) Montenegro seismic motion.

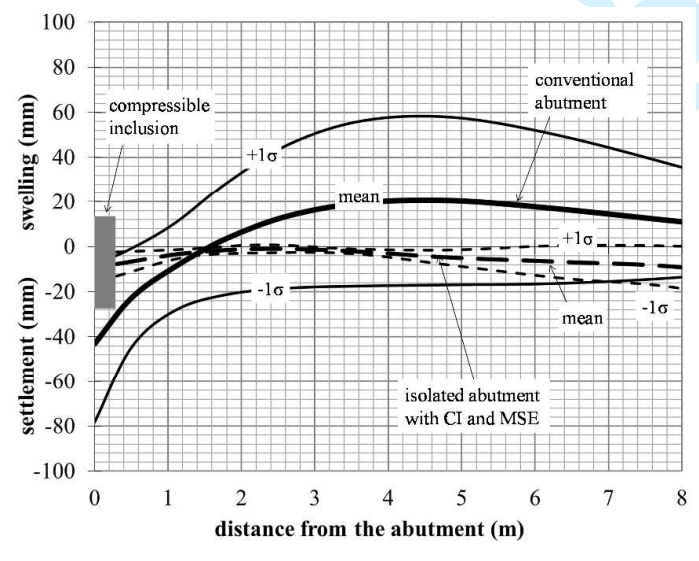

(a)

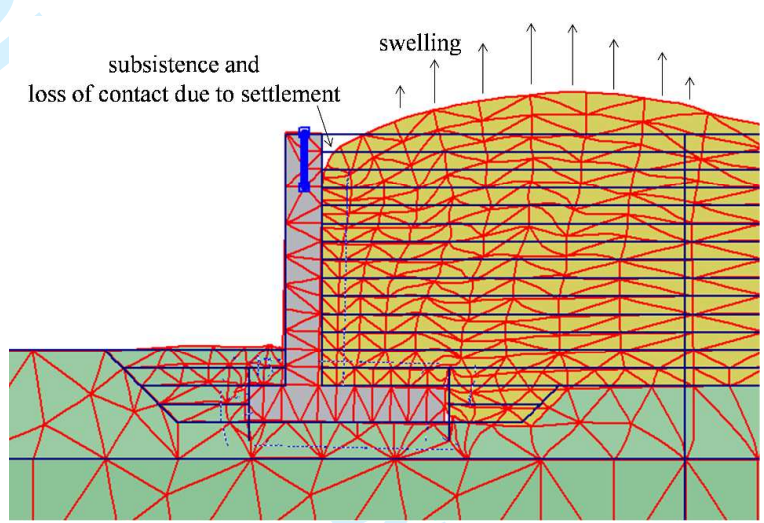

(b)

Figure 16 (a) The mean value and the standard deviation of the settlement and swelling of the backfill soil for the conventional and the isolated abutment (seven ground motions) and (b) the condition of the backfill soil after the earthquake.

\subsection{Actions on the abutment}

The economic design of the abutment is dependent on the sizing and reinforcements of its structural components and on the cost of the backfill soil, including the long-term condition and the required maintenance and/or replacement of the soil. The loading of the abutment was discussed in the previous sections of the paper, based on the pressures acting upon it, whilst the long-term performance of the backfill was evaluated on the basis of its permanent vertical deflections. This section discusses the bending moments and shear forces that are developed under the in-service and the seismic loads. 
Figure 17a shows the bending moments that act on the conventional (continuous lines) and isolated (dashed lines) abutment after ten full cycles of thermal expansion and contraction of the deck. The results show that the bending moment at the end of the loading was $466.9 \mathrm{kN} \cdot \mathrm{m} / \mathrm{m}$ for the conventional and $76.3 \mathrm{kN} \cdot \mathrm{m} / \mathrm{m}$ for the isolated abutment, i.e. six times less compared to the conventional. Looking at the bending moments under seismic loads, as per Figure $17 \mathrm{~b}$, it was found that the conventional abutment developed a mean bending moment of $334.0 \mathrm{kN} \cdot \mathrm{m} / \mathrm{m}$ with a standard deviation of $160.8 \mathrm{kN} \cdot \mathrm{m} / \mathrm{m}$ for the seven seismic motions considered. The maximum bending moment was $555.3 \mathrm{kN} \cdot \mathrm{m} / \mathrm{m}$ for the Montenegro seismic input motion. With regard to bending moments on the isolated abutment, it was found that they had linear distribution along the height of the abutment, whilst the maximum value recorded was $79.8 \mathrm{kN} \cdot \mathrm{m} / \mathrm{m}$ for the Kern County earthquake motion.

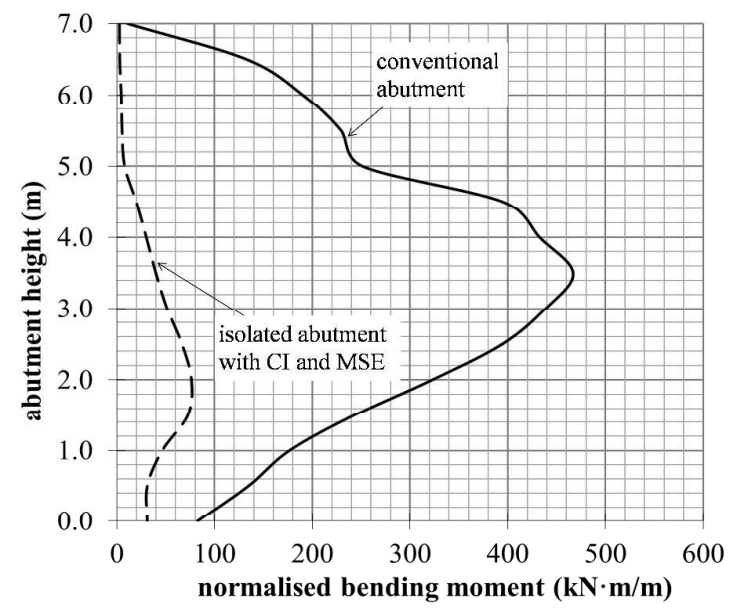

(a)

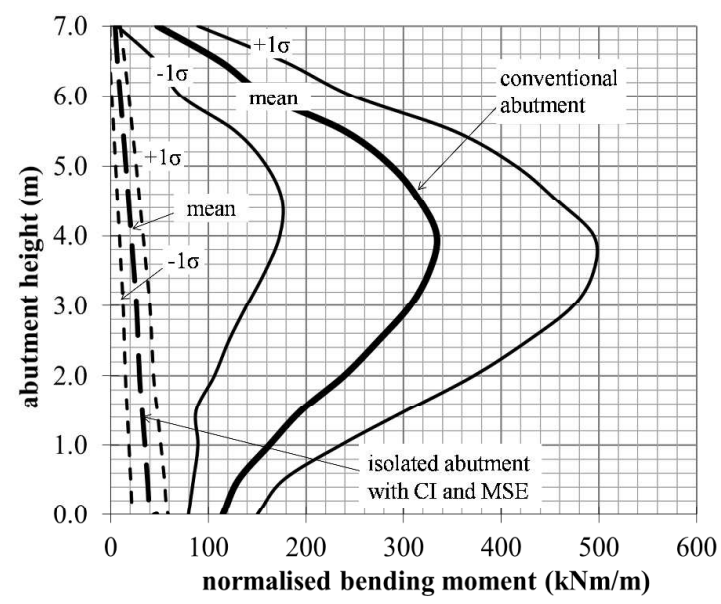

(b)

Figure 17. The normalised bending moments on the abutment for (a) ten full cycles corresponding to the maximum thermal displacements of the deck $( \pm 30 \mathrm{~mm})$ and (b) the seismic loading (mean value and standard deviation).

Figure 18 shows the shear forces acting on the conventional and the isolated abutment. Figure 18a illustrates the shear forces during the bridge service, i.e. 10 full cycles of thermal displacements of $\pm 30 \mathrm{~mm}$, whilst Figure 18b shows the mean shear forces for the seven earthquake excitations along with the standard deviations. With regard to thermal movements of the deck, it is observed that the compressible inclusion achieved a reduction in the maximum shear force from $103.5 \mathrm{kN} / \mathrm{m}$ to $61.2 \mathrm{kN} / \mathrm{m}$. The results for the seismic loading of the abutment are similar, as the isolated abutment exhibited negligible shear forces as opposed to the conventional one, on which a maximum of $159.8 \mathrm{kN} / \mathrm{m}$ shear force was developed for the Montenegro seismic motion. The mean value of the shear force for the seven seismic input motions analysed was $85.7 \mathrm{kN} / \mathrm{m}$ for the conventional abutment. 


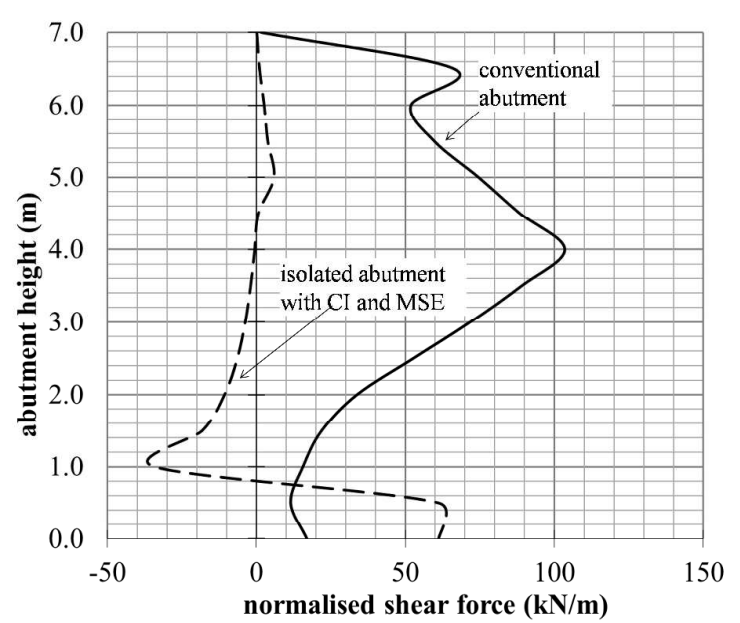

(a)

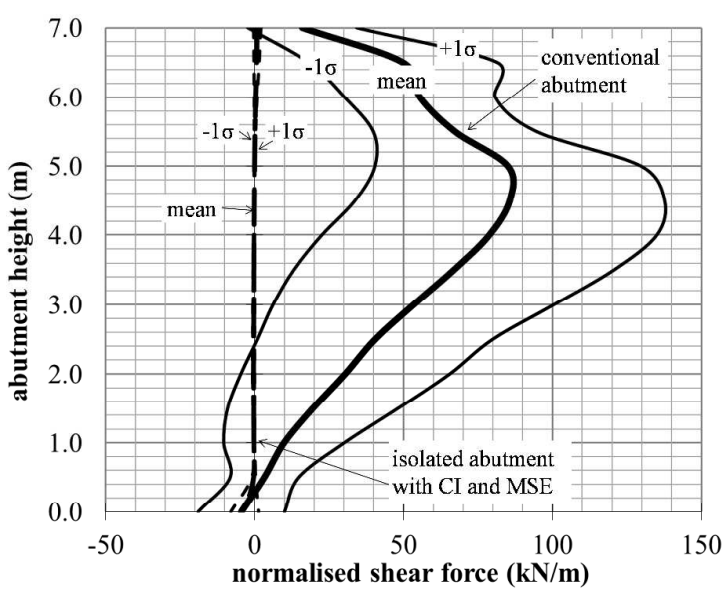

(b)

Figure 18. The normalised shear forces acting on the abutment for (a) ten full cycles corresponding to the thermal displacements of the deck and (b) the seismic loading of the abutment (mean and standard deviation).

\section{CONCLUSIONS}

A novel compressible inclusion (CI) comprised reused tyre derived aggregates was utilised as a means to isolate integral frame abutment bridges from the backfill. The CI remediates the abutment-embankment interaction under serviceability and dynamic loads and enables the extended application of longer integral bridges subjected to earthquake excitations. For this purpose, a numerical study was conducted with PLAXIS finite element code. Initially, one and ten cycles of thermal movements of the abutment were analysed for two different loading patterns, i.e. deck expansion and then contraction or contraction first and then expansion, to represent potential different times for the restraint of the integral abutment. Subsequently, the model abutments were subjected to a set of Eurocode-compatible earthquake motions to assess the efficiency of the CI to isolate the abutment from the backfill. Based on the results of this study the following conclusions were drawn:

The analysis of the abutment under the thermal expansion and contraction of the bridge showed that the soil pressures are significantly lower when the abutment is isolated. For one full cycle of thermal movements, a maximum of $692 \mathrm{kPa}$ soil pressure was developed on the conventional abutment as opposed to $43 \mathrm{kPa}$ on the isolated abutment. Interestingly, the soil pressures that were developed on the conventional abutment were larger when the abutment first moves away from the backfill and then pushes it, i.e. when the deck first contracts and subsequently expands. On the contrary, the isolated abutment showed negligible dependency on the sequence of loading, whilst the variation of the soil pressures against the isolated abutment was not significantly influenced by the position of the abutment during the expansion or the contraction of the deck. A maximum earth pressure of $97 \mathrm{kPa}$ was found to act on the isolated abutment, when the latter was subjected to ten full cycles of loading.

The soil pressures developed during the earthquake excitation of the coupled system were significantly smaller on the isolated abutment in comparison to the conventional. The mean soil pressure that was developed on the conventional abutment for the seven selected seismic motions was $333 \mathrm{kPa}$ as opposed to the $148 \mathrm{kPa}$ for the isolated abutment, i.e. less than half. The permanent, i.e. post-earthquake, mean value of the earth pressures was $190 \mathrm{kPa}$ for the conventional and $47 \mathrm{kPa}$ for the isolated abutment, whilst the distribution of the latter was linear along the height of the abutment. 
A significant reduction in the settlements of the backfill soil was also observed for the isolated abutment. For the displacements of the abutment during the bridge service, the backfill soil exhibited a maximum swelling of $15 \mathrm{~mm}$, whilst the conventional one exhibited a settlement of $85 \mathrm{~mm}$, followed by a maximum swelling of $123 \mathrm{~mm}$. It is also worth noting that the loading of the abutment by one cycle of $\pm 30 \mathrm{~mm}$ had almost negligible effect on the settlements of the isolated backfill, whilst the conventional backfill exhibited significant settlements and swelling.

With regard to seismic loads, the conventional abutment exhibited a maximum settlement of $97 \mathrm{~mm}$ behind the abutment, whilst $90 \mathrm{~mm}$ of swelling of the soil was observed at a distance approximately $4.5 \mathrm{~m}$ away from the abutment. The isolated abutment caused a maximum settlement of the soil equal to $25 \mathrm{~mm}$, i.e. one fourth of the one observed for the conventional one. Hence, the permanent vertical deflections of the backfill soil were significantly reduced when the abutment was isolated by the proposed layer of tyre-derivedaggregates and the backfill soil was reinforced by geogrids.

The bending moments and the shear actions acting on the isolated abutment were found to be significantly smaller than the ones developed on the conventional abutment. The bending moments of the isolated abutment were one sixth to one tenth of those developed on the conventional abutment. Similar were the results for the shear forces. Also, it is worth noting that the results presented correspond to a long-span integral frame bridge, of $240 \mathrm{~m}$ long. Based on the results, the serviceability, i.e. the displacements of the abutment due to the expansion and contraction of the deck, had a predominant effect on the loading of the integral frame abutment. The aforementioned finding is based upon the fact that the soil pressures, the settlements and/or swelling of the backfill soil and the loading of the abutment were worse for the serviceability, in comparison to the results for the seismic effects.

With regard to design of the compressible inclusion, it was found that both the thickness and the Poisson's ratio of the tyre derived aggregates had an almost negligible effect on the performance of the abutment, i.e. the soil pressures, the settlements and the loading of the abutment. Nevertheless, sound design and placement of the isolator is required to avoid concentration of stresses in the backfill soil. This research will be extended by the analysis of a bridge model including the piers and the deck.

Acknowledgements: The authors of the paper would like to acknowledge the support provided by Professor Kyriazis Pitilakis at Aristotle University of Thessaloniki, Greece, who kindly shared the experimental results for the characterisation of tyre derived aggregates.

\section{REFERENCES}

[1] ASCE. Report card for America's infrastructure, 2013.

[2] INTAB. Economic and durable design of composite bridges with integral abutments. Research Program RFSC RFS-P2-08065, European Commission, Brussels, 2010

[3] IABSE. Special Issue on Integral Bridges. Structural Engineering International 2011; 2.

[4] Mistry VC, Al Mangus. Get in, stay in, get out, stay out. Federal Highway Administration, Department of Transportation, 2006; 70(3). FHWA-HRT-2006-001.

[5] Dicleli M, Eng P, Albhaisi SM. Maximum length of integral bridges supported on steel Hpiles driven in sand. Engineering Structures 2003; 25:1491-1504.

[6] Mitoulis SA, Tegos I.A. Two new earthquake resistant integral abutments for medium to long-span bridges. Structural Engineering International: Journal of the International Association for Bridge and Structural Engineering (IABSE) 2011; 21(2):157-161.

[7] Baptiste KT, Kim W, Laman JA. Parametric study and length limitations for prestressed concrete girder integral abutment bridges. Structural Engineering International 2011; 21(2):151-156. 
[8] Mitoulis SA, Tegos IA, Stylianidis K-C. Cost-effectiveness related to the earthquake resisting system of multi-span bridges. Engineering Structures 2010; 32(9):2658-2671.

[9] Arockiasamy M, Butrieng N, Sivakumar M. State-of-the-art of integral abutment bridges: design and practice. Journal of Bridge Engineering 2004; 9(5):497-506.

[10] Emerson M. Bridge temperatures estimated from the shade temperature. Report LR696, Transport and Road Research Laboratory, Department of Environment, UK, 1976.

[11] Darley P, Carder DR, Barker KJ. Seasonal thermal effects over three years on the shallow abutment of an integral bridge in Glasgow. Report 344, Transport Research Laboratory, Crowthorne, Berkshire, UK, 1998.

[12] England GL, Tsang NCM, Bush DI. Integral bridge, a fundamental approach to the timetemperature loading problem. Thomas Telford: London, 2000. ISBN O-7277-2845-8.

[13] Springman SM, Norrish A, and Ng CWW (1996) Cyclic loading of sand behind integral bridge abutments. TRL Rep. 146, Transport Research Laboratory, Berkshire, UK.

[14] Bloodworth A, Xu M, Banks J, Clayton C. Predicting the earth pressure on integral bridge abutments. Journal of Bridge Engineering 2012; 17(2):371-381.

[15] Lemnitzer A, Ahlberg E, Nigbor R, Shamsabadi A, Wallace J, Stewart J. Lateral performance of full-scale bridge abutment wall with granular backfill. Journal of Geotechnical and Geoenvironmental Engineering 2009; 135(4):506-514.

[16] Shamsabadi A, Rollins KM, Kapuskar M. Nonlinear soil-abutment-bridge structure interaction for seismic performance-based design. Journal of Geotechnical and Geoenvironmental Engineering 2007; 133(6):707-720.

[17] Barker KJ and Carder DR (2006) The long term monitoring of stresses behind three integral bridge abutments. Technical Paper No. 10. Concrete Bridge Development Group, Camberley, Surrey, UK.

[18] Darley P, Carder DR and Barker KJ (1998) Seasonal thermal effects over three years on the shallow abutment of an integral bridge in Glasgow. TRL Rep. 344, Transport Research Laboratory, Crowthorne, Berkshire, UK

[19] Xu M, Bloodworth A, Clayton C. Behavior of a stiff clay behind embedded integral abutments. Journal of Geotechnical and Geoenvironmental Engineering 2007; 133(6):721-730.

[20] England GL, Tsang NC. Towards the design of soil loading for integral bridgesexperimental evaluation. Department of Civil and Environmental Engineering, Imperial College, London, 2001. (available from: http://www.cbdg.org.uk).

[21] Arockiasamy M, Sivakumar M. Time-dependent behavior of continuous composite integral abutment bridges. Practice Periodical on Structural Design and Construction, ASCE 2005; 10(3):161-170.

[22] Xu M, Clayton CRI, Bloodworth A. The earth pressure behind full-height frame integral abutments supporting granular backfill. Canadian Geotechnical Journal 2007; 44(3):284-298.

[23] Helwany S. Evaluation of bridge approach settlement mitigation methods. Report 07-14, Wisconsin Highway Research Program, University of Wisconsin-Milwaukee, 2007.

[24] Arsoy S, Duncan J, Barker R. Behavior of a semiintegral bridge abutment under static and temperature-induced cyclic loading. Journal of Bridge Eng. 2004; 9(2):193-199.

[25] Kappos AJ, Sextos AG. Seismic assessment of bridges accounting for nonlinear material and soil response and varying boundary conditions. NATO Science for Peace and Security Series C: Environmental Security 2009; 3:195-208.

[26] Mitoulis SA. Seismic design of bridges with the participation of seat-type abutments. Engineering Structures 2012; 44:222-233.

[27] England GL. A thermal displacement compensation unit for integral bridges. Patents, Bridge structures 2005. P.N.: CA 2605437 A1. 
[28] Horvath J. Lateral pressure reduction on earth-retaining structures using geofoams: correcting some misunderstandings. ASCE Earth Retention Conference 3 2010: 862-869. DOI: $10.1061 / 41128(384) 86$.

[29] Hoppe EJ. Field study of integral backwall with elastic inclusion. Final Report, Virginia Transportation Research Council, Charlottesville, 2005.

[30] Pötzl M, Naumann, F. Fugenlose betonbrücken mit flexiblen widerlagern. Beton- und Stahlbetonbau 2005; 100(8).

[31] Murphy G. The influence of geofoam creep on the performance of a compressible inclusion. Geotextiles and Geomembranes 1997; 15(1-3):121-131. Elsevier Science Ltd: London, 2008;189-195.

[32] Humphrey D, Blumenthal M. The use of tire-derived aggregate in road construction applications. Proc Green Streets and Highways, $1^{\text {st }}$ T\&DI Green Streets \& Highways Conference, ASCE, 2011.

[33] Humphrey D. Civil engineering applications using tire derived aggregate (TDA). DRRR-2011-038, California Integrated Waste Management Board, California, 2010.

[34] Senetakis K, Anastasiadis A, Pitilakis K, Souli A. Dynamic behaviour of sand/rubber mixtures. Part II: Effect of rubber content on G/Go- $\gamma$-DT curves and volumetric threshold strain. Journal of American Society of Testing and Material International 2012; 9(2). Paper ID JAI103711.

[35] Senetakis K, Anastasiadis A, Pitilakis K. Dynamic properties of dry sand/rubber (SRM) and gravel/rubber (GRM) mixtures in a wide range of shearing strain amplitudes. Soil Dynamics and Earthquake Engineering 2012; 33:38-53.

[36] Argyroudis SA, Mitoulis SA, Pitilakis KD. Seismic response of bridge abutments on surface foundation subjected to collision forces. Proc COMPDYN 2013, $4^{\text {th }}$ ECCOMAS Thematic Conf Comp Methods Struct Dyn Earthq Eng, 2013; Kos Island, Greece.

[37] CEN. EN 1997-1 Geotechnical design - Part1: General rules, Brussels, 2004.

[38] CEN. EN 1998-5 Design of structures for earthquake resistance - Part 5: Foundations, retaining structures and geotechnical aspects, Brussels, 2004.

[39] Clayton CRI, Xu M, Bloodworth A. A laboratory study of the development of earth pressure behind integral abutments. Géotechnique 2006; 56(8):561-571.

[40] CEN. EN 1998-1 Design of structures for earthquake resistance - Part 1: General rules, seismic actions and rules for buildings, Brussels, 2004.

[41] Argyroudis S, Kaynia AM, Pitilakis K. Development of fragility functions for geotechnical constructions: application to cantilever retaining walls. Soil Dynamics and Earthquake Engineering 2013; 50:106-116.

[42] PLAXIS 2D (2008). Reference Manual, Version 8.

[43] CEN. EN 1991-1 Actions on structures - Part 1-5: General actions-Thermal actions, European Committee for Standardization, Brussels, 2003.

[44] Mitoulis S, Argyroudis S, Kowalsky M. Evaluation of the stiffness and damping of abutments to extend direct displacement based design to the design of integral bridges. Proc COMPDYN 2015, $5^{\text {th }}$ ECCOMAS Thematic Conf Comp Methods Struct Dyn Earthq Eng, 2015; Crete Island, Greece, 25-27 May.

[45] Mylonakis G, Nikoloaou S, Gazetas G. Footings under seismic loading: Analysis and design issues with emphasis on bridge foundations. Soil Dynamics and Earthquake Engineering 2006; 26:824-853.

[46] Mitoulis S, Argyroudis S, Pitilakis K. Green rubberised backfills to enhance the longevity of integral abutment bridges. Proc $2^{\text {nd }}$ European Conference on Earthquake Engineering and Seismology, 2014; Istanbul, Turkey, 24-29 August. 